\title{
Use of a Decellularized Porcine Extracellular Matrix in the Congenital Heart Surgery, Experience of One Center
}

\author{
Alejandra Valeria Iturriaga-Hernández* \\ Department of Pediatric Cardiac Surgery, Hospital de Especialidades Pediátrico de León, León, Guanajuato, Mexico
}

*Corresponding author: Alejandra Valeria Iturriaga-Hernández, Department of Pediatric Cardiac Surgery, Hospital de Especialidades Pediátrico de León, León, Guanajuato, Mexico, Tel: 5527550273; E-mail: valeria.iturriaga@hotmail.com

Received: 31 Oct, 2019 | Accepted: 07 Dec, 2019 | Published: 12 Dec, 2019

Citation: Iturriaga-Hernández AV (2019) Use of a Decellularized Porcine Extracellular Matrix in the Congenital Heart Surgery, Experience of One Center. J Surg Open Access 6(1): dx.doi.org/10.16966/2470-0991.202

Copyright: (C) 2019 Iturriaga-Hernández AV. This is an open-access article distributed under the terms of the Creative Commons Attribution License, which permits unrestricted use, distribution, and reproduction in any medium, provided the original author and source are credited.

\section{Abstract}

For years the use of membranes and other prosthesis for the repair of the congenital cardiac defects have been studied widely, trying to offer the best tissue to the children. The aim is to give durability, resistance, easy-to-use membranes. Beside some cardiac procedures in neonates or infants may need a reoperation and the surgeon looks for good tissues. In this study we present the use of decellularized porcine extracellular matrix scaffold for the repair of some congenital heart procedures. In the Hospital Regional de Alta Especialdad de León, we use this matrix in 17 patients during one year (2018). We are looking for a wide experience in the region we are showing our preliminary results.

Keywords: Congenital heart defects; Extracellular matrix; Cardiac surgery; Bioprosthesis

\section{Introduction}

According to current literature, it is estimated that congenital heart diseases are present in 2.1-12.3 of every 1,000 live newborns, a figure that has been increasing thanks to prenatal echocardiographic diagnosis or in the first hours of birth [1]. In Guanajuato we do not have a recent published statistic but according to this estimate, if we take into account that in our state 116,531 births were reported in 2017, probably our incidence would be from 932 to 1398 children with congenital heart diseases [2]. The diagnosis is becoming more frequent in the first days of life, thus increasing neonatal surgery, according to the database of congenital surgery of the European Association (www.eactscongenitaldb.org), more than $50 \%$ of surgical procedures are carried out in the first year of life, whereby the use of prosthetic materials is an important issue, since it is necessary to take into account that the patient has his whole life to continue growing. We have a wide variety of materials with which we seek to avoid leaks, detachments, retractions, calcifications and in general that are resistant, trying to avoid complications. Polytetrafluorethilene membranes, bovine pericardium patch, and some others were used for many years. However, it should be take into account that many of these patients will undergo more than one surgery, and reconstruction of the pericardium to reduce complications in reoperations has become more frequent.

Last year a decellularized extracellular matrix of porcine intestinal submucosa (CorMatrix) was introduced in Guanajuato, useful for cardiac reoperations and as support for vascular repairs. In this paper we describe our experience using this membrane in the surgery of congenital heart malformations at the Hospital Regional de Alta Especialidad del Bajio.

\section{Method}

During 2018, 17 patients were operated, with an average age of 6.2 years in a range from 9 months to 16 years. All patients underwent corrections using the membrane (Figure 1) (CorMatrix), to repair intracardiac defects. 5 atrial septal defect closures, 3 ventricular septal defect closures, 2 atrioventricular canal corrections, 2 aortic ring enlargements for aortic valve change, 1 partial anomalous pulmonary vein connection correction, 1 total anomalous pulmonary vein connection correction, 1 aortoplasty with Brom technique, 1 reconstruction of the interatrial septum, and 1 correction of tetralogy of fallot were performed. The characteristics of each procedure are shown in table 1.

\section{Results}

Two deaths not associated to the membrane were recorded. A patient in the immediate post-surgical period, secondary to a pulmonary hypertension crisis, and a patient 35 days after his surgery secondary to septic shock.

None of the patients presented major complications regarding the use of the extracellular matrix. There were no reoperations for mediastinal examinations secondary to bleeding. All patients were followed in the consultation and assessed according to the Cardiologist's criteria. Echo was performed in the immediate post-surgical period, and according to clinical evolution, echo was repeated within the first 6 months of follow-up. The 


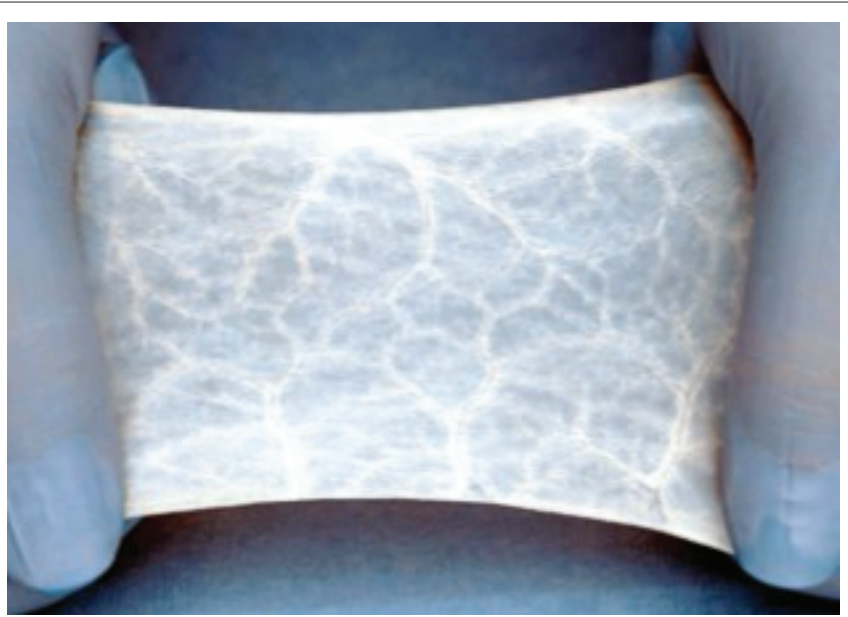

Figure 1: Decellularized porcine extracellular matrix.

Table 1: Patient's characteristics.

\begin{tabular}{|c|c|c|c|c|c|c|c|}
\hline Patient & Sex & Age (Years) & $\begin{array}{l}\text { Weight } \\
\text { (Kg) }\end{array}$ & Cardiac Tissue Repair & Diagnosis & $\begin{array}{l}\text { Follow-up } \\
\text { (Months) }\end{array}$ & Echo \\
\hline 1 & Female & 11 & 21.2 & $\begin{array}{l}\text { Interatrial septum (Enlargement of septum } \\
\text { and redirection of flux) }\end{array}$ & PAPVR & 8 & Yes \\
\hline 2 & Female & 1 & 7.7 & Interatrial septum (Flux redirection) & TAPVR & 7 & Yes \\
\hline 3 & Female & 14 & 43 & Aortic annulus (Enlargement) & $\begin{array}{l}\text { Aortic stenosis+Subvalvar } \\
\text { membrane }\end{array}$ & 6 & Yes \\
\hline 4 & Female & 5 & 12.8 & Interatrial septum & ASD & 6 & No \\
\hline 5 & Male & $9 \mathrm{~m}$ & 7.2 & Interventricuar septum & VSD & 6 & No \\
\hline 6 & Female & 4 & 14.5 & Aorta (Brom) & Supraaortic stenosis & 5 & Yes \\
\hline 7 & Female & 9 & 30 & Interventricular septum & VSD & 5 & Yes \\
\hline 8 & Male & 5 & 16.5 & Interatrial septum & ASD & 4 & No \\
\hline 9 & Male & 1 & 7.5 & Interatrial septum & VSD & 1 & No \\
\hline 10 & Female & 9 & 23 & Right ventricle (Enlargement) & TF & 4 & No \\
\hline 11 & Female & 5 & 19 & Interatrial septum & ASD & 4 & Yes \\
\hline 12 & Male & 16 & 62 & Aortic annulus (Enlargement) & Aorticstenosis & 3 & No \\
\hline 13 & Male & 3 & 11.5 & Interventricular septum & VSD & 3 & Yes \\
\hline 14 & Male & 13 & 66.5 & Interatrial septum & ASD & 3 & Yes \\
\hline 15 & Female & 4 & 12.7 & Interatrial septum & Partial AVC & 3 & Yes \\
\hline 16 & Male & 2 & 8.9 & Interatrial septum & Single atrium & 3 & No \\
\hline 17 & Female & 4 & 14 & Interatrial septum & ASD & 2 & Yes \\
\hline
\end{tabular}

clinical follow-up was $88 \%$ (removing the 2 deceased patients), so far with 2 to 6 months follow-up. There was no evidence of thrombosis, disruption, retraction, leaks or calcifications in both echocardiography and chest radiographs. (We have no system of recording for the echocardiograms, so we are based in the written report that our cardiologist do).

In patients where an enlarged ring and ascending aorta were performed, there was no evidence of insufficiency or stenosis.

The patient where the vascular reconstruction patch was used for reintegration of cava superior to the right atrium, presented superior cava syndrome 48 hours after surgery, the patient underwent to a diagnostic-therapeutic catheterization, finding stenosis in the anastomosis, and resolving after balloon angioplasty, the interatrial patch was observed without leaks or retractions.

\section{Discussion}

Congenital heart disease is currently treated at an early age, to benefit the patient with a physiological circulation as soon as possible. Thus each surgical procedure has to maintain maximum growth potential for the patient [3].

In complex congenital heart diseases, the use of prosthetic external materials is frequent. Since 1960, many materials such as PTFE, bovine pericardium and autologous pericardium (fresh or treated with glutaraldehyde) have been used, with varied short and long term results. The main concern is related to possible patch dehiscence, calcification, thickening, retraction and degeneration [3].

Bovine pericardium and prosthetic materials share the problem of inducing inflammatory process, leading to patch endothelialization, but with fibrotic reaction, scar formation and possible calcification [3]. 
While the patient's autologous tissue is considered the ideal material, it has the advantages of being a living tissue, allows adequate growth and grows together with the patient, resists infections, does not require anticoagulation and does not induce rejection reactions, however not always it is available in appropriate quantities or appropriate form for corrections [4].

The ideal material for cardiac tissue reconstruction is still controversial. The ideal patch should be manageable (flexible), hemostatic and tear-resistant, without retracting or calcifying, and if possible not induce inflammatory reaction. It should grow with the patient and improve the regeneration of native tissue [3].

Recently the extracellular matrix obtained from the submucosa of the porcine intestine has been introduced in cardiac surgery. This matrix is an acellular biomaterial that envelops cells in most tissues. This compound of structural proteins (elastin and collagen), adhesion glycoproteins, glycosaminglucans and proteoglycans and matrix proteins (thrombospondins, osteopontin and terscins). The Cormatrix membrane is intestinal submucosa [3].

This material provides an internal bio-scaffold that allows the patient's own cells to repopulate and repair damaged tissues. In animal models, the extracellular matrix was used in esophageal, tendon and skin reconstruction, providing evidence of tissue remodeling and regeneration [5].

Since 2018, this bio-scaffold is used in our institution, reaching 17 patients in whom some intracardiac or vascular correction was made. The repair was successful in all patients, both vascular and intracardiac tissues. None of the patients had complications related to the placement of the patch in the first months of follow-up.

A recent study by Scholl FG, et al. [6] described the review of a valve patch analyzed by electron micrograph and microscopic light. Four months after the implant they found a complete resorption of the extracellular matrix with replacement of the patch material by organized collagen. In addition, the valvular surface had been populated with endothelial-like cells.

A major secondary issue in the correction of cardiac malformations at an early age is the high probability of reoperating, it is even known that certain patients are diagnosed with heart disease that need a multi-stage repair.

Re-sternotomy is associated with possible cardiac injury, with an incidence around 0.7 to $10 \%$ of total operations, especially in ascending aortic aneurysms, diseases causing atrial growth, the use of ducts and previous mediastinitis $[7,8]$. The prevention of mediastinal adhesions is of great importance to reduce risks, and the systematic closure of the pericardium helps reduce the risk of adhesion development.

\section{Conclusions}

So far, extracellular matrix bioscaffold has proven to be a good option for the surgical correction of children with congenital heart disease. Although our follow up is based on clinical and echocardiogram findings, successful repair was achieved based in the good evolution of the children.

Until now we have not had reoperations, but it is a very short time of follow-up and the cardiac cases are not so complex as in other institutions. We decide to show our preliminary experience because it is a new biomembrane in our country with good expectations in some papers $[3,5,6]$.

Subsequently, a long-term follow-up will be carried out, to finish assessing the potential offered by this membrane as an intracardiac and vascular patch, evaluating durability, and the potential to integrate into the patient's tissues (in order to avoid reoperations). However, so far it has been very useful in the surgeries in which we have used it, offering easy handling, resistance and decreased bleeding.

\section{References}

1. Calderón-Colmenero J, Cervantes-Salazar JL, Curi-Curi PJ, RamírezMarroquín S (2010) Problemática de las cardiopatías congénitas en México. Propuesta de regionalización. Arch Cardiol Méx 80: 133140.

2. México en Cifras (2019) INEGI.

3. Quarti A, Nardone S, Colaneri M, Santoro G, Pozzi M (2011) Preliminary experience in the use of an extracellular matrix to repair congenital heart diseases. Interact Cardio Vasc Thorac Surg 13: 569572.

4. Dodge-Khatami A (2016) Advances and research in congenital heart disease. Transl Pediatr 5: 109-111.

5. Badylak SF, Vorp DA, Spievack AR, Simmons-Byrd A, Hanke J, et al. (2005) Esophageal reconstruction with ECM and muscle tissue in a dog model. J Surg Res 128: 87-97.

6. Scholl FG, Boucek MM, Chan KC, Valdes-Cruz L, Perryman R (2010) Preliminary experience with cardiac reconstruction using decellularized porcine extracellular matrix scaffold: human applications in congenital heart disease. World J Pediatr Cong Heart Dis 1: 132-136.

7. Follis FM, Pett SB Jr, Miller KB, Wong RS, Temes RT, et al. (1999) Catastrophic hemorrhage on sternal reentry: still a dreaded complication? Ann Thorac Surg 68: 2215-2219.

8. Yamauchi T, Miyamoto Y, Ichikawa H, Takano H, Saua Y (2006) Large vessel-sternum adhesion after cardiac surgery: a risk factor analysis. Surg Today 36: 596-601. 